3 Research Square
Preprints are preliminary reports that have not undergone peer review.

They should not be considered conclusive, used to inform clinical practice, or referenced by the media as validated information.

\title{
Psychosocial needs of the parents of children with mental disorder
}

\section{Zahra Zangeneh}

Kermanshah University of Medical Sciences

Amir Jalali ( $\nabla$ jalali_amir@yahoo.com )

Kermanshah University of Medical Sciences https://orcid.org/0000-0002-0307-879X

\section{Rostam Jalali}

Kermanshah University of Medical Sciences

\section{Hooman Daryoushi}

Kermanshah University of Medical Sciences

Primary research

Keywords: Psychological Needs, Social needs, Parents, Adolescence, Mental disease

Posted Date: February 12th, 2020

DOI: https://doi.org/10.21203/rs.2.23303/v1

License: (9) This work is licensed under a Creative Commons Attribution 4.0 International License. Read Full License 


\section{Abstract}

\section{Background}

In addition to the major problems that a child with mental disorder, the family, and society are faced with, mental disorders in children cause several problems and care pressure on the parents in particular. While the parents suffer the highest damages by their child' disease, they tend to hide their pains, sufferings, and needs from others. The present study is an attempt to elaborate on psychosocial needs in the parents of children with mental disorder.

\section{Methods}

The study was carried out as a qualitative study using content analysis method. To this end, 21 parents of children with mental disorder at age range 10-18 years took part in the study. The participants were selected through purposeful sampling and after signing an informed letter of consent, deep semistructured interviews were conducted with them. The interviews were recorded with the consent of the participants and the data was analyzed using conventional content analysis.

Results

Analysis of the interviews revealed 302 codes, 16 subcategories, seven categories, and two themes. The theme "psychological needs" was comprised of categories the need for assurance, the need for emotional support, and the need for being accepted. The theme "social needs" was comprised of categories the need for social support, the need for welfare, the need for information support, and the need for family support.

Conclusion

Given the changes in their lives caused the disease of their children, parents of children with mental disorders deal with several needs and challenges. The needs categorized in mental and emotional fields and social and information supports were the main needs.

\section{Background}

Mental disorder is a syndrome or behavioral/psychological pattern with clinical significance that causes disability or discomfort in the individual (1). Having a child with physical or mental disability causes notable changes in the organization and structure of family. This has a determinant effect on the process of rehabilitation and independence of the family (2).

Depending on the impairment, having a child with impairment may lead to physical and mental problems, or financial pressures on the parents (3). These parents have to watch physical and behavioral changes in their children, which is a source of severe emotional pressure and discomfort (4). Parents of children with developmental and mental disorders have to deal with several challenges (5). Such challenges might 
include behavioral challenges of the child, participation in looking after the child, communication with experts in the treatment and follow up process, and social interaction between the child and family. Add to these challenges other things like a sense of incompetence, anxiety, financial problems, changes of roles, poor social adaptation, increased social isolation, and disappointment with the care system (6).

The risk of behavioral problems and emotional disorders in a child with behavioral and mental problems may increase, when they are exposed to a stressful family situation and the care givers are not capable of covering the emotional-social and cognitive needs (7). Studies have shown that parents who received supports in the area of taking care of their sick children, tended to have more emotion and affection towards their child (8). Provision of quality and proper services to cover the needs of such families can improve their quality of life and attenuate the pressure on family system (6).

There are ever-increasing needs for studying the outcomes of mental disorders of children in families. Such studies deepen the awareness of the pressure and the load of responsibility on these parents (9). Recognizing and answering the needs of parents of children with mental disorders can improve the quality of lives of these parents. This also contributes to a higher quality of life in the society (10). Doubtlessly, providing efficient and proper support by organizations in charge of such services entails realizing the psychosocial and economic needs beforehand. Through this, it would be possible to concentrate the proper supports on the aspects that need more support (11).

To find the needs and problems with regard to a specific phenomenon, there is a need to study the individuals who have experienced the phenomenon. Qualitative studies are good answers for this need (12). Qualitative content analysis is one of the common approaches to survey phenomena in society. Content analysis is a reliable study method for an orderly and objective description of the content collected through communication (13). Through this, the researcher determines frequency of incidence, meaning, and relationship between the words and concepts in a text and then the messages of the text, author, addressees, even the culture and time that host the words and concepts are inferred (14). Using this approach, the present study is aimed at determining the needs of the participants based on their expressions. In addition to elaborating on the psychosocial needs of the parents of children with mental disorder, the present paper is a step towards developing proper approaches to meet such needs.

\section{Materials And Methods}

\section{Design}

Taking the objective of study into account, this qualitative study was carried out using conventional content analysis (13).

\section{Setting}

The study environment was children and adolescence psychology wards in Mohammad Kermanshahi and Farabi hospitals. 


\section{Participants}

The participants were all fathers and mothers who, during the study, had a 10-18 years old child under psychological treatment for a diagnosed mental disorder in the hospitals. The researcher used purposeful sampling to select the parents who met the inclusion criteria and were interested in participating in interviews. Different variables were taken into account in selecting the participants such as parent's age, type of the disease, term of disease, parent's education level, and family condition (economic and cultural conditions) so that the maximum variation was ensured in the sampling process.

\section{Data Collection}

Information gathering was done through deep and semi-structured interviews. After selecting the participants, they were asked to sign a written letter of consent. Interviews were private and face to face at different hours of the day (morning and afternoon) at a quiet and peaceful environment in Farabi and Mohammad Kermanshahi hospitals in Kermanshah city. The interviews would be recorded only after the participants would give their consent. In addition, the interviewer would take note through the interview. The term of each interview depended on the energy of the participant to avoid causing any discomfort for the participant. The average time of interviews was 50-60 min. The interviews went on based on the guiding questions of which the validity had been confirmed by experts beforehand.

\section{Some of the questions asked in the interviews:}

- How your social and carrier relationships are affected by having a child with mental disorder?

- What is your opinion about the needs of the parent of a child with mental disorder?

- What helps do you need to deal with your child's disease?

- What is the best way to support parents of a child with mental disorder?

- What measure can ensure mental peace of parents of a child with mental disorder?

Open questions would be asked throughout the interviews to delve deeper into the details of answers. The interviewer would also bring back the participant to the main subject should the participant wandered from the topic. The interviewer would use probing questions at the right moment to lead the interview towards shedding more light into the phenomenon under study.

In addition, the interviewer was completely familiar with the local accent, which gave him a better chance to glean richer information.

\section{Data analysis}

The data was analyzed using qualitative approach based on Graneheim and Hundman's qualitative content analysis (13). After transcription and to gain a general impression of the different aspects of experiences and attitudes, the texts were read for several times. Then the sentences were broken into 
semantic units comprised of sentences or a paragraph and the primary codes were developed using terms and works close to those used by the participants. Eventually, the codes were categorized based on similarities and differences and categories formed groups based on similarity, connection, and continuity. Through this, categories were organized in a meaningful conceptual pattern and the relationships between the data were determined, which led to extraction of themes.

\section{Rigor}

To ensure rigor of the data, the four measures proposed by Guba and Lincoln (creditability, transferability, dependability, confirmability) were used (15). The authors' long history of working at the study site was effective in winning the participants' trust. Letting the participants to review the extracted data for confirmation of the data and codes improved confirm ability of the data.

Following maximum variation as the sampling strategy to cover a wide range of participants based on demographic characters improved creditability of the data. In other words, the codes and categories were examined by several therapists and researchers to ensure dependability of the data. To ensure transferability of the data, the findings were shared with several non-participating parents of children with mental disorder. Member check by the participants were used to support authenticity of the data and codes. The codes that were not representative of their viewpoints were modified.

\section{Results}

Totally, 21 interviews were conducted with the parents of 10-18 years old children with mental disorder. Mean age of the participants was 44 with max and min ages of 58 and 37 respectively. Mean age of the mothers was 42.62 years with max and min ages of 52 and 37 respectively. In addition, mean age of the fathers was 48.5 years with max and min ages of 41 and 58 years. Mean age of the children was 13.42 years with max and min ages of 17 and 10 respectively.

Totally, 415 primary codes were extracted and after removing similar codes, 302 codes, 16 subcategories, seven categories, and two themes were extracted (Table 2). 
Table 1

Demographic characters of Participants

\begin{tabular}{|c|c|c|c|c|c|c|}
\hline No. & Relation & $\begin{array}{l}\text { Parents } \\
\text { Age(Y) }\end{array}$ & $\begin{array}{l}\text { Adolescence } \\
\text { Age }(Y)\end{array}$ & $\begin{array}{l}\text { Adolescence } \\
\text { gender }\end{array}$ & $\begin{array}{l}\text { Parents } \\
\text { Job }\end{array}$ & $\begin{array}{l}\text { Educational } \\
\text { Statue }\end{array}$ \\
\hline 1 & Mother & 37 & 12 & Daughter & $\begin{array}{l}\text { House } \\
\text { wife }\end{array}$ & Diploma \\
\hline 2 & Mother & 38 & 15 & Son & Clerk & Diploma \\
\hline 3 & Mother & 39 & 16 & Son & Teacher & Higher Edu \\
\hline 4 & Mother & 38 & 10 & Son & $\begin{array}{l}\text { House } \\
\text { wife }\end{array}$ & Higher Edu \\
\hline 5 & Mother & 40 & 14 & Daughter & Clerk & Diploma \\
\hline 6 & Father & 46 & 15 & Daughter & Employee & Higher Edu \\
\hline 7 & Mother & 45 & 17 & Son & $\begin{array}{l}\text { House } \\
\text { wife }\end{array}$ & High School \\
\hline 8 & Mother & 42 & 12 & Son & Barber & Diploma \\
\hline 9 & Mother & 39 & 12 & Daughter & $\begin{array}{l}\text { House } \\
\text { wife }\end{array}$ & $\begin{array}{l}\text { elementary } \\
\text { Level }\end{array}$ \\
\hline 10 & Father & 50 & 10 & Son & Farmers & Diploma \\
\hline 11 & Father & 49 & 15 & Son & $\begin{array}{l}\text { Army } \\
\text { Staff }\end{array}$ & Higher Edu \\
\hline 12 & Mother & 40 & 12 & Daughter & Worker & High school \\
\hline 13 & Mother & 44 & 15 & Son & Clerk & Diploma \\
\hline 14 & Father & 47 & 13 & Son & Worker & High school \\
\hline 15 & Mother & 41 & 11 & Son & $\begin{array}{l}\text { House } \\
\text { wife }\end{array}$ & Diploma \\
\hline 16 & Mother & 51 & 12 & Daughter & Farmers & $\begin{array}{l}\text { elementary } \\
\text { Level }\end{array}$ \\
\hline 17 & Mother & 52 & 16 & Daughter & $\begin{array}{l}\text { House } \\
\text { wife }\end{array}$ & $\begin{array}{l}\text { elementary } \\
\text { Level }\end{array}$ \\
\hline 18 & Father & 41 & 14 & Son & Farmers & Diploma \\
\hline 19 & Mother & 47 & 17 & & Secretor & Diploma \\
\hline 20 & Father & 58 & 14 & Son & Clerk & High School \\
\hline 21 & Mother & 40 & 14 & Son & $\begin{array}{l}\text { House } \\
\text { wife }\end{array}$ & $\begin{array}{l}\text { elementary } \\
\text { Level }\end{array}$ \\
\hline
\end{tabular}


Table 2

Categories and sub-categories

\begin{tabular}{|c|c|c|}
\hline Categories & Sub-categories & Theme \\
\hline Tranquility & \multirow[t]{3}{*}{ The need for assurance } & \multirow{7}{*}{$\begin{array}{l}\text { Psychological } \\
\text { Needs }\end{array}$} \\
\hline Alleviation of afflictions & & \\
\hline Inducing hope & & \\
\hline Family attachment & \multirow[t]{2}{*}{ The need for emotional support } & \\
\hline devotion to relatives & & \\
\hline Be accepted to & \multirow[t]{2}{*}{ The need for being accepted } & \\
\hline Being approved & & \\
\hline De-stigmatization & \multirow[t]{2}{*}{ The need for social support } & \multirow[t]{8}{*}{ Social Needs } \\
\hline Culture Developing & & \\
\hline Financial supporting & \multirow[t]{2}{*}{ The need for welfare } & \\
\hline Insurance and social services & & \\
\hline Consulting services & \multirow{2}{*}{$\begin{array}{l}\text { The need for information } \\
\text { support }\end{array}$} & \\
\hline $\begin{array}{l}\text { team } \\
\text { teamer interaction with the treatment }\end{array}$ & & \\
\hline spouse and children supporting & \multirow[t]{2}{*}{ The need for family support } & \\
\hline Tribs and friends supporting & & \\
\hline
\end{tabular}

\section{Psychological needs}

\section{The need for assurance}

The need for assurance was one of concepts revealed by analyzing the interviews. The parents were concerned about the ambiguous future of their child and their need for hope was quite evident. There are three subcategories in this category including the need for tranquility, the need for alleviation of afflictions, and inducing hope. Participant No.8 said: "We live with a constant source worry; every day we expect a new disaster and bad news..."

"Sometimes I spend hours talking to my friend and sharing my worries. This gives me a bit of tranquility..." (No.3). "The sense of guilt never leaves me. I keep thinking that we are responsible for my daughter's disease..." (No.1). "I have lost my hope in medication and doctors. I have even visited fortunetellers and religious healers; it did not help either..." (No.9). 


\section{The need for emotional support}

Emotional problems caused by having a sick child and watching development of the symptoms cause emotional shocks in the parents. Through solidarity and attachment, the family members can support each other emotionally, mentally, and socially and better understand each other. This category is comprised of two subcategories of family attachment and visiting relatives. "I think I live in a prison and have lost my connection to the world. I do not know when I am going to be released..." (No4).

"Only when I talk to my friend, I can feel a bit calm. She always says that I should have trust in God..." (No.2). "Instead of doing something for us, the relatives only blame us..." (No.7).

\section{The need for being accepted}

Data analysis showed that due to the hardships and emotional needs, the parents kept looking for acceptance and being understood by others. The parents highlighted the need for others' approval as such approval alleviated the sense of guilt. In addition, being judged by others really bothered them. This category consists of two subcategories of being accepted and the need for approval. "We would love being treated with respect by others. It is not our sin that our child is sick, we have done nothing wrong..." (No.1).

"I really feel good when someone tells me the I am a good mother for being so persistent to cure my child's disease..." (no.13).

"I would like it that my husband's family see how hard I work to take care of by child. I do not like them to think that I am an inconsiderate mother..." (no.21)

\section{Social needs}

\section{The need for social support}

Another theme that was revealed through data analysis was the need for social support. The parents who felt lonely due to their child's disease felt the need for social support more than ever. They underscored new problems and needs, mostly in social relationships, after their child's disease. This theme consisted of two subcategories of de-stigmatization and necessity of cultural developing. "People say that this mental disease is hereditary as my sister in laws was hospitalized for a while. Now, we do not see any chance for our older daughter to find a suitor." (No.9).

"I feel that we have lost our dignity among our relatives and in the neighborhood. I can see this in their eyes as if mental disease is some sort of a $\sin . . . "$ (No.8).

"If it was a cancer, although it is a hard disease, at least there would not be this much talks behind our back..." (No. 7).

\section{The need for welfare}


This category consisted of financial helps and social services. The participants clearly expressed that their children's disease and the consequences have caused problems in their livelihood and payment of medical costs. The parents believed that organizations like Welfare Organizations must provide them with better, more diverse, and quality services for the children with mental disorders. "The hospitalization and medication costs are too heavy. My poor husband cannot support all these no matter how hard he tries..." (No.8).

"I do not have a job and my husband is busy with the medication works of our kid. Because of that, we have a lot of financial problems..." (No.15).

"There is nobody left to borrow money from. We have to borrow money for hospitalization, medications, and other costs and this is very embarrassing..." (No.5).

\section{The need for information support}

The unknown and complicated nature of mental diseases add to the fear, anxiety, and worries that the parents feel. They are disparate and confused about the proper way of taking care of and supporting the treatment process and at the same time preserving the normal family life. Data analyses showed the necessity for consultation services and interaction with the treatment personnel to learn about the patient's condition and how to help them. "This is our youngest girl. She was ok at first, but then she showed the symptoms. The doctor says that it is hereditary, but I do not understand it..." (No.9).

"I have read a few books and surfed the Internet about my boy's problem, but these cannot replace a face to face consultation where I can ask my questions..." (No.13).

"It is much better when the doctor gives us enough time to talk to us and listen to what we have to say..." (No.5).

\section{The need for family support}

Data analyses showed that the decreased family supports and special situation of the children cause more problems and crises for the parents. The participants highlighted the serious need for family support especially the spouse, children, relatives, and friends' support. "The gap between my wife and I widens whenever our daughter is hospitalized. I feel there is a wide distance between us..." (No.6)

"I have always had many friends and liked socialization. But now, I do not have the energy even to call them. I feel pity for myself. If wish I could hang around with my friends again and talk to them..." (No.19).

\section{Discussion}

The mental and social needs of the parents of children with mental disorder in Kermanshah City-Iran were elaborated. The results showed that the need for social support and its different fields were among the main needs of these parents. Derguy et al. emphasized on emotional supports for the parents of autistic children (as a social disorder) (16). To explain the findings, it is notable that the families of children with 
mental or developmental disorder experience more mental pressure than the normal families. Emotional needs and the need for assurance and peace are of the main needs of these parents.

Studies on the need for alleviation of pain have shown that to eliminate the sense of guilt and restore peace and tranquility, parents need assurance by others (17). The need for support to alleviate pain and hardship of taking care of impaired children has been supported by many studies (18). With regard to the need to induce hope, it is notable that initiation of a child's disease and the lengthy treatment process cause disappointment in the parents with the treatment and recovery. Hope is the subjective forecast about the future that are also rooted in one's beliefs. Hope is also effective in one's behavior in social interactions.

The need for emotional support was another mental need that was frequently mentioned. Kerr et al. argued that emotional needs were among the main needs of the parents of children with cancer (19). Algood et al. concluded that children with impairment need a lot of attention from their parents and this causes more pressure on the parents. This adds to the needs of parents like supportive and emotional needs (8).

Another concept revealed by the study was family attachment and visiting relatives. In their interviews, the parents noted in different ways the need for family and friends' support. Teles et al. argued that the birth of an impaired child causes notable changes in the organization and structure of family(2). In such case, emotional and social support by the care givers to the child are vital. The response of these children's family to such a challenge depends on many factors including the relationship between family members. Pelentsov's et al. finding showed that the sense of imprisonment and limitation, changes in interpersonal relationships, loneliness, and the need to talk to others were among the main needs of these parents (20).

Results showed that the need for social support was another important need of the participants. Social presence and the attempts to keep the previous social relationships (the relationships before the child with mental disorder) intensifies and underlines this need. Failure to meet this need might seriously affect the social activities of these parents so that they might have problems in creating social relationships. This problem disrupts the peace and balance in the parents' lives and also affects the relationship between the parents and the child and their attempt to help the child to adapt and regain their abilities. Boyd argued that being the parent of an impaired child is highly stressful and causes misbalance in the family. Therefore, these parents need more social supports (21).

The participants complained about misunderstanding in the society and their friends about mental diseases especially in children. Meltzer et al. believed that the majority of such parents experienced pressures in their lives. More than one third of these parents said that they had not invited their friends over after appearance of mental problems in their child (22).

Another main need of the participants was the need for welfare. The cost of medical services and lost revenue add to the needs of these parents for financial and welfare needs. The need for medical 
insurance coverage was one of the main needs mentioned by the parents. Studies on other causes have also confirmed the need for welfare in the parents of children with mental disorder. Allik et al. argued that the type of childbearing of the children with mental problems and diagnosed pervasive developmental disorder (PDD) were related to poor welfare condition of the parents (23). Forbes et al. showed that parents of children with mental disorder deal with a wide range of problems and needs. One of the main needs was the need for social and financial support (24). Pelentsov et al. found that the majority of the parents of children with mental disorder (95\%) had serious financial problems (20). These studies are consistent with the present study so that the parents' need for financial support, medical insurance coverage, and social support is confirmed.

The participants also mentioned the need for information support and consultation services. Information support and social consultation are needed to improve awareness and knowledge about how to deal with such children. Information support and social consultation were of the main needs of the participants. Kerr et al. argued that the need for information support in the parents of children with physical diseases and disorders even like cancer, which is a prevalent and known disease, was one of the main needs of these parents (19).

The need for family support and the support by the spouse, children, and relatives was highlighted as one of the main needs of parents. Dunn et al. argued that the parents of autistic children demonstrated a lower marital satisfaction and adaptation in their families (25). Lewis et al. found that welfare and adaptability of parents were closely related to family support (5). Marsack and Samuel argued that the responsibility of taking care of a child with mental disorder had a negative effect on the quality of life of the parents. They also argued that informal social support, and family support of such responsibility, and quality of life of the parent had mediatory roles (26). The results of this study highlighted the need for supporting the parents of children with mental disorder through informal social supports.

\section{Conlusion}

The results showed that the participants had to deal with several needs and challenges caused by the changes that taking care of a child with mental disorder creates. Such changes and needs have negative effects on all fields of parents' lives including mental and social fields. Timely recognition of such needs attenuates the care pressures on the parents and helps them to realize the objectives of care and rehabilitation programs for their child.

\section{List Of Abbreviations}

Pervasive Developmental Disorder (PDD)

Kermanshah University of Medical sciences (KUMS)

\section{Declarations}




\section{Ethical Consideration}

After securing a permission from the Ethics Committee (IR.KUMS.REC. 1397.054), a letter of consent for informed participation and publication of the results was prepared and after a brief introduction to the study, the participants were asked to sign the letter. Before recording the interview, the participant's permission would be secured. They were also ensured about confidentiality of their interviews and that they can leave the study at any stage.

\section{Consent to publication}

Not applicable.

\section{Availability of data and materials}

The datasets used and analyzed during the current study are available from the corresponding author on reasonable request.

\section{Competing interests}

The authors declare that they have no conflict of interest about this work.

\section{Funding:}

This study was drawn from a research project (No. 97021) sponsored by deputy of research and technology of KUMS. The cost of the payment is spent on the design and implementation of the study

\section{Authors' contributions}

ZZ, Contributed in study concept, study design, data collection and manuscript preparation.

AJ, Contributed in study concept, study design, data Analysis, and manuscript preparation and submitting the manuscript.

RJ, Contributed in study concept, study design, data collection and manuscript preparation.

HD, Contributed in study concept, study design, data collection and manuscript preparation.

\section{Acknowledgement}

We are grateful to the Deputy for Research and Technology, Kermanshah University of Medical Sciences, for cooperating in this research. We thank all the participants in the study.

\section{References}


1. Agerskov H, Ludvigsen MS, Bistrup C, Pedersen BD. From donation to everyday life: Living kidney donors' experiences three months after donation. Journal of Renal Care. 2016;42(1):43-52. DOI:10.1111/jorc.12137.DOI: 10.1111/jorc.12137.

2. Teles FM, Resegue R, Puccini RF. Care needs of children with disabilities-Use of the Pediatric Evaluation of Disability Inventory. Revista Paulista de Pediatria (English Edition). 2016;34(4):447-53.

3. Yamaoka Y, Tamiya N, Izumida N, Kawamura A, Takahashi H, Noguchi $H$. The relationship between raising a child with a disability and the mental health of mothers compared to raising a child without disability in japan. SSM-population health. 2016;2:542-8.

4. Fido A, Al Saad S. Psychological effects of parenting children with autism prospective study in Kuwait. Open journal of psychiatry. 2013;3(02):5.

5. Lewis P, Abbeduto L, Murphy M, Richmond E, Giles N, Bruno L, et al. Psychological well-being of mothers of youth with fragile $X$ syndrome: Syndrome specificity and within-syndrome variability. Journal of Intellectual Disability Research. 2006;50(12):894-904.

6. Al-Dababneh KA, Fayez M, Bataineh O. Needs of Parents Caring for Children with Physical Disabilities: A Case Study in Jordan. International Journal of Special Education. 2012;27(3):120-33.

7. Cheesman J. Raising an ADHD child: Relations between parental stress, child functional impairment, and subtypes of the disorder: University of Cape Town; 2011.

8. Algood CL, Harris C, Hong JS. Parenting success and challenges for families of children with disabilities: An ecological systems analysis. Journal of Human Behavior in the social environment. 2013;23(2):126-36.

9. Mohammad Aghighi SN. Dialysis in iran. In: book Dg, editor. lesan-pezashki M. tehran2007. p. 3-11.

10. Speziale HS, Streubert HJ, Carpenter DR. Qualitative research in nursing: Advancing the humanistic imperative. Fifth edition ed. Philadelphia , USA: Lippincott Williams \& Wilkins; 2011.

11. Gomes p, Lima,L.H.,Bueno,M.k., Araujo.L.A.,\& Souza, N.M. Autism in Brazil:a systematic review of family challenges and coping strategies. depediatria. 2015;91(2):111-21.

12. Hsieh HF, Shannon SE. Three approaches to qualitative content analysis. Qual Health Res. 2005;15(9):1277-88.DOI: 10.1177/1049732305276687.

13. Graneheim UH, Lundman B. Qualitative content analysis in nursing research: concepts, procedures and measures to achieve trustworthiness. Nurse education today. 2004;24(2):105-12.DOI: 10.1016/j.nedt.2003.10.001.

14. Rodgers BL. Developing nursing knowledge: Philosophical traditions and influences: Lippincott Williams \& Wilkins; 2005.

15. Speziale HS, Streubert HJ, Carpenter DR. Qualitative research in nursing: Advancing the humanistic imperative:: Lippincott Williams \& Wilkins; 2011.

16. Derguy C, Michel G, M'bailara K, Roux S, Bouvard M. Assessing needs in parents of children with autism spectrum disorder: A crucial preliminary step to target relevant issues for support programs. Journal of Intellectual and Developmental Disability. 2015;40(2):156-66. 
17. Sheehan R. Mental Illness in Children: Childhood Illness and Supporting the Family. Brain Sci. 2017;7(8):97.DOI: 10.3390/brainsci7080097.

18. Leung CYS, Li-Tsang CWP. Quality of life of parents who have children with disabilities. Hong Kong Journal of Occupational Therapy. 2003;13(1):19-24.

19. Kerr LM, Harrison MB, Medves J, Tranmer JE, Fitch MI. Understanding the supportive care needs of parents of children with cancer: An approach to local needs assessment. Journal of Pediatric Oncology Nursing. 2007;24(5):279-93.

20. Pelentsov LJ, Laws TA, Esterman AJ. The supportive care needs of parents caring for a child with a rare disease: a scoping review. Disability and Health Journal. 2015;8(4):475-91.

21. Boyd BA. Examining the relationship between stress and lack of social support in mothers of children with autism. Focus on autism and other developmental disabilities. 2002;17(4):208-15.

22. Meltzer H, Ford T, Goodman R, Vostanis P. The burden of caring for children with emotional or conduct disorders. International journal of family medicine. 2011;2011.

23. Allik H, Larsson J-O, Smedje H. Health-related quality of life in parents of school-age children with Asperger syndrome or high-functioning autism. Health and quality of life outcomes. 2006;4(1):1.

24. Forbes H, Dziegielewski SF. Issues facing adoptive mothers of children with special needs. Journal of Social Work. 2003;3(3):301-20.

25. Dunn ME, Burbine T, Bowers CA, Tantleff-Dunn S. Moderators of stress in parents of children with autism. Community mental health journal. 2001;37(1):39-52.

26. Marsack CN, \&Samuel, P.S. Mediating effects of social support on quality of life for parents of adults with autism. journal of autism and devlopmental disorders. 2017;47(8):2378-89. 